\title{
The Chemistry of Indigenous Peoples
}

\section{Marcos Aurélio Gomes da Silva*}

Federal University of Juiz de Fora, Brazil

*Corresponding Author: Marcos Aurélio Gomes da Silva, Federal University of Juiz de Fora, Brazil.

Received: May 14, 2019; Published: June 07, 2019

DOI: $10.31080 /$ ASPS.2019.03.0302

The contribution of non-European cultures to science and technology, primarily to chemistry, has gained very little attentions until now. Especially, the high technological intelligence and inventiveness of South American native populations shall be put into a different light by our contribution. The purpose of this study was to show that mainly in the area of chemical practices; the indigenous competence was considerable and has led to inventions profitable nowadays to millions of people in the western world and especially to the pharmacy corporations. We would like to illustrate this assumption by giving some examples of chemical practices of transformation of substances, mainly those unknown in the old world. The indigenous capacity to gain and to transform substances shall be shown here by the manufacture of poisons, such as curare or the extraction of toxic substances of plants, like during the fabrication of manioc flower. We shall mention as well other processes of multi-stage transformations and the discovery and the use of highly effective natural substances by Amazonian native populations, such as, for example, rubber, ichthyotoxic substances or psychoactive drugs. The indigenous peoples of South America do not seem to have contributed to modern chemistry and technology. In contrast, there are some references and observations made by chroniclers and travelers from the colonial period regarding the transformation, manipulation and use of substances that require certain chemical knowledge, such as fermented beverages, dyes (pigeon peas, Urucum), and the poisons (Curare and Timbó). Even so, these populations end up being identified as "primitive savages" who still need the support of modern civilization in order for them to develop.

Body painting of the Brazilian Indians was one of the first things that caught the attention of the Portuguese colonizer. Pero Vaz de Caminha, in his famous letter to King D. Manoel I, already talked about little hedgehogs that the Indians carried in their hands. They brought some of them green hedgehogs, trees, who in color almost wanted to appear of chestnut trees; just that they were more and more small. And the same

were filled with red, small, which, crushed between the fingers, made very red dye from the that they walked red; and when the more they wet the more red they stayed".

The Indians of Alto Xingú paint thebody skin with animal drawings, birds and fish. These drawings besides serving to identify the social group at thewhich they belong, are a way of unite them with the spirits, to whom they credit their happiness.

The ink used by these Indians is prepared with urucu seeds , which is collected in the monthsof May and June. The seeds are grated in fine and boiledwater to form a paste. With this paste balls are made which, involved in sheets, are stored throughout the year for the tattoo ceremonies.

The ink extracted from Urucu is also used dyeing hair and making tion of facial masks. Urucu is used coloring page butter, margarine, cheeses, sweets andsmoked fish, and its colorant main - bixina - in solar filters.

it was possible to identify possible contents of Chemistry that could be related to the preparation of Tarubá, such as mixtures, separation of mixtures and fermentation processes. The process of preparation of the beverage made from grated cassava involves the separation of the mixture between the solid of the cassava mass and the liquid of the tucupi, made through the filtration process with the tipiti, a traditional Indian instrument. The dough is sieved, roasted and put to rest for three days, when the fermentation process occurs, in which the sugar contained in cassava is processed by microorganisms and transformed into other substances such as alcohol and gas. After this period, water and sugar are added to the batter, and the beverage is ready to be consumed. 
Art of dewatering: cassava

Now we would like to turn our attention to the opposite process, the devel- opment. Although it does not require techniques as sophisticated as the production of substances, the deworming is a fundamental procedure for the people who live and want to survive in the rainforest Amazon, since many plants of there produce poison by virtue of its secondary metabolism. After all, the way that many plant species have to avoid insect bite is the production of defensive chemical resources. Whoever wants to survive in the rainforest needs to know how to neutralize or ward off these toxic substances produced by the plants themselves. The mastering of the art of deforestation is what enables the inhabitants of the Amazon not to die of hunger.

In this sense, we will examine the example of the cassava root in more detail so that we can then briefly refer to other products and processes. The last section will address some of the political implications of our perspective.

In Brazil, manioc (Manihot esculenta) is known under different names in several regions. In the south of the country, it is also called "aipim", in central Brazil, "maniva", "manaíba", "uaipi", and in the north, "macaxeira" or "carim".

In this essay, we intend to show that, to a certain extent, companies, a process of invention of the Indian Indians of South America, and still are considerable, as businesses, until today, millions of people and institutions benefit in the Western world. We seek to provide information from a few examples regarding chemical practices and biochemical procedures for the transformation of substances that are unknown in Europe.

Volume 3 Issue 7 July 2019

(C) All rights are reserved by Marcos Aurélio Gomes da

Silva. 